\title{
Calibration and comparison of different CFD approaches for airflow analysis in a glass greenhouse
}

\author{
Stefano Benni, Enrica Santolini, Alberto Barbaresi, Daniele Torreggiani, Patrizia Tassinari \\ Department of Agricultural Sciences, University of Bologna, Italy
}

\begin{abstract}
CFD has been increasingly applied to greenhouses to optimise indoor environmental conditions for cultivation and management. Numerical simulations have proved fundamental for the enhancement of energy-efficient design criteria and management procedures. The objective of the study is the comparison between different computational approaches for the study of airflow patterns in a representative study case of a glass greenhouse, also through the calibration of the models and the validation of simulation results against experimental data. A three-span greenhouse of about $300 \mathrm{~m}^{2}$ located in Emilia-Romagna (Italy) has been considered as study case. Several analyses with the same boundary and initial conditions were performed using two codes, broadly used for research and design purposes. With both programs, $2 \mathrm{D}$ or $3 \mathrm{D}$ models have been used and, for every case, the grid convergence was verified by performing multiple steady state analyses with increasingly finer meshes. The results led to define the most suitable solutions to set up computational models for the simulation of airflow patterns inside a greenhouse. The study provided a preliminary outline of the differences due to the adoption of various computational approaches characterised by different levels of accuracy and complexity. The results indicate the advisability of further developing the research by carrying out deeper experimental insights necessary to quantify more in detail the validity and the reliability of the adopted analytical methodologies.
\end{abstract}

\footnotetext{
Correspondence: Stefano Benni, Department of Agricultural Sciences, University of Bologna, viale G. Fanin 48, 40127 Bologna, Italy.

E-mail: stefano.benni@unibo.it
}

Key words: 3D model; CFD model; finite element model; finite volume model; greenhouse.

Acknowledgements: the authors wish to thank prof. Beatrice Pulvirenti $\mathrm{PhD}$, Assistant Professor at the Department of Industrial Engineering of the University of Bologna, for the support provided in CFD modelling.

Received for publication: 1 June 2016.

Accepted for publication: 10 October 2016.

CCopyright S. Benni et al., 2017

Licensee PAGEPress, Italy

Journal of Agricultural Engineering 2017; XLVIII:568

doi:10.4081/jae.2017.568

This article is distributed under the terms of the Creative Commons Attribution Noncommercial License (by-nc 4.0) which permits any noncommercial use, distribution, and reproduction in any medium, provided the original author(s) and source are credited.

\section{Introduction}

Natural ventilation has a crucial role in the environmental sustainability of greenhouses (Bartzanas et al., 2004; He et al., 2015), it is deeply affected by the external conditions and it is dependent on vent sizes and dispositions (Katsoulas et al., 2006; Benni et al., 2016). The first experiments on air circulation in a greenhouse were performed in the mid-1950s, to evaluate the influence of the openings on the ventilation efficiency as it was reported in literature (Mistriotis et al., 1997b). The application of CFD methods to analyse ventilation issues has become increasingly important in time with the progressive improvements of computer systems (Mistriotis et al., 1997a). The effects of various geometries (Khaoua et al., 2006) and solar radiation (Boulard et al., 1997), humidity and its control, or the study of the natural ventilation (Mistriotis et al., 1997c) have been investigated using CFD. The complexity and realism of the most recent computational approaches call for a careful calibration of the digital models in order to get reliable tools to set up and carry out the simulations.

The goal of this study is to investigate the airflow patterns for a case study of a glass greenhouse in isothermal conditions, in order to define reliable and accurate modelling procedures, with different computational approaches, compared on the same study case. The specific objectives of the study are the definition of meshes suitable to achieve reliable results independently on the cell size and the comparison of results obtained through different codes in a significant greenhouse study case.

\section{Materials and methods}

A three-span greenhouse of about $300 \mathrm{~m}^{2}$ of the University of Bologna, Italy $\left(44.337340^{\circ} \mathrm{N}\right.$ lat., $11.718647^{\circ} \mathrm{E}$ long. and $72 \mathrm{~m}$ alt.) has been considered as study case. The azimuth of spans longitudinal axis is $55^{\circ}$, with access doors located on the north-eastern front. Each span is $8 \mathrm{~m}$ wide, $12.7 \mathrm{~m}$ long, and $4 \mathrm{~m}$ high at eave, with $5.5 \mathrm{~m}$ maximum height; the pitch slope is $40 \%$. The greenhouse has steel structure, concrete floor and $4 \mathrm{~mm}$ thick coverings of tempered glass. Each span has two central top roof openings of $25^{\circ}$ over $1.50 \mathrm{~m}$ length. Both roof and side vents are continuous along the whole length. The spans correspond to indoor areas separated by glass walls and connected through internal doors. This study focuses on the south-eastern sector, which hosts benches with aluminium structure. The greenhouse is equipped with a monitoring system which measures indoor temperature and relative humidity in each sector, as well as outdoor meteorological data of illuminance, temperature, wind speed and direction with 10 min acquisition time. In particular the devices for outdoor data monitoring are placed at the top of the central span, $1 \mathrm{~m}$ above the ridge of the main façade. 
Two codes broadly used for research and design purposes have been adopted: Autodesk CFD (release 2016), with a finite element (FEM) approach, and Fluent, which adopts the finite volume method (FVM). The greenhouse was modelled as an empty building, in order to obtain results independently on plants inside the structure. Both 2D (of the mid-cross section) and 3D models have been analysed. A domain including the greenhouse at its centre was used (Rico-Garcia et al., 2011) with plan dimensions of $72 \times 50.7 \mathrm{~m}$ and height of $22 \mathrm{~m}$.

Convergence for FEM code was assumed based on the union of specific criteria as follows: the maximum instantaneous slope of the convergence data of all of the dependent variables from one iteration to the next is below the set level of $10^{-4}$; then the slopes of the convergence data averaged over several iterations of minimum, maximum and mean values of all of the dependent variables are below 0.01 ; moreover the derivative of the maximum time averaged convergence slope (concavity) falls below the pre-determined level of 0.01 ; in addiction the fluctuation of the dependent variable about the mean value shows a standard deviation below the set level of $10^{-5}$.

The domain was discretised into a hybrid grid that combines triangular and quadrilateral element types in $2 \mathrm{D}$, or tetrahedron and hexahedron elements in $3 \mathrm{D}$, thus providing maximum flexibility in matching mesh cells with the boundary surfaces. Grid quality was enhanced through the placement of at least one layer of quadrilateral or hexahedral elements in resolving boundaries near solid walls and desks. A symmetry condition was applied at the top and on the side faces of the domain.

Convergence criteria for FVM code are relative to the decreasing of residuals equal to $10^{-3}$ for all the equation except for energy and P-1 equation, for which this is $10^{-6}$. In fact, it is expected that the residuals decay to some small value (round-off) and then stop changing (level out). The convergence criteria for the simulations are based on the control of residuals, which are defined at $10^{-6}$ except for $k$ and $\varepsilon$, set at $10^{-3}$.
The calibration of the models was carried out through a data collection campaign in controlled environment, with high frequency and spatial resolution of surveys, performed on 10 February 2015 through Delta Ohm DO9847 multi-function data loggers. Vane probe anemometer adopted was model AP472 S1, with 100 $\mathrm{mm}$ diameter, resolution of $0.01 \mathrm{~m} / \mathrm{s}$, accuracy of $\pm(0.1 \mathrm{~m} / \mathrm{s}+$ $1.5 \%$ full scale).

\section{Results and discussion}

A model validation was performed by comparing the air speed data recorded at the wall inlet with the results of $2 \mathrm{D}$ unsteady state thermal analyses developed with the FEM code. The unsteady state thermal approach has been adopted as it was the most suitable to simulate the real conditions experienced during the measurement trials. The results are shown in Figure 1 and have been synthetically assessed by computing the mean error, equal to $0.020 \mathrm{~m} / \mathrm{s}$ and the root mean squared error equal to $0.078 \mathrm{~m} / \mathrm{s}$. As both parameters are smaller than the anemometer accuracy, the simulations have been considered reliable within the acceptability range adopted for this study. A straightforward verification of the close correspondence between measured and simulated parameters can be obtained by comparing the trend of simulated results with the moving average of the experimental values over a 60 s period in Figure 1.

Mesh independency was verified for the 2D FEM model by performing several steady state analyses with increasingly finer meshes simulating the indoor air, from about 13,000 elements up to more than 52,000. For the 3D FEM model, mesh independency was verified through the mesh adaptation tool of Autodesk CFD software. A mixed mesh has been adopted with elements of $0.2 \mathrm{~m}$ inside the building and of $1 \mathrm{~m}$ outside, with a volume increasing rate of 1.35 in the transition zones outside the greenhouse. Mesh independency was achieved with $7.523 \times 10^{6}$ elements at a rate of

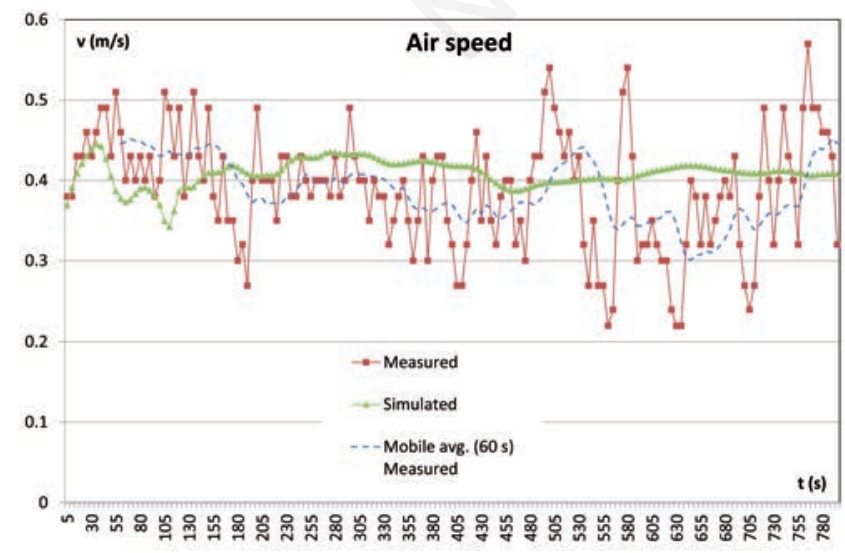

Figure 1. Trends of air speed at the wall inlet during the transient phase: measured values and simulated results of unsteady state thermal analysis. The dashed line represents the mobile average for 60-s period of the measured data.

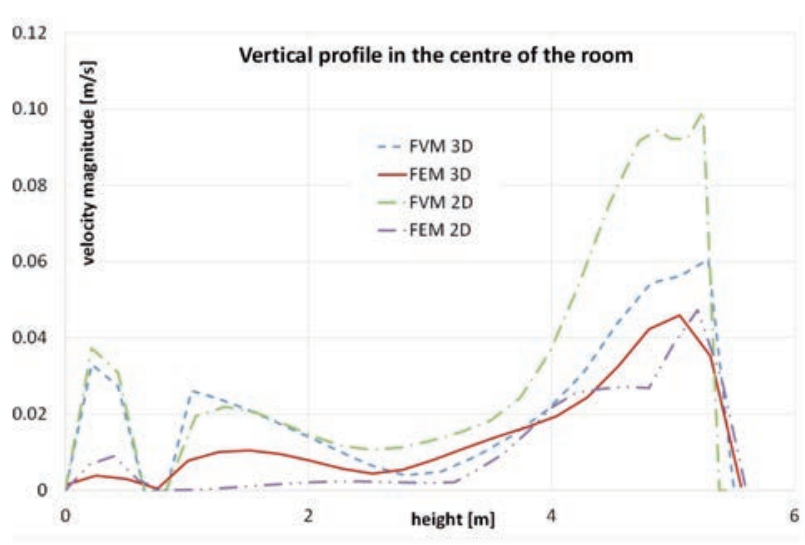

Figure 2. Comparison of air velocities computed by the two codes with $3 \mathrm{D}$ and $2 \mathrm{D}$ models, along a vertical profile at the centre of the cultivation area. FVM, finite volume method; FEM, finite element method. 
$95.18 \%$ for pressure and $99.97 \%$ for velocity.

A preliminary grid convergence study was made in order to quantify the influence of the grid resolution on the results also for the FVM code (Di Sabatino et al., 2007). Firstly, a simplified geometrical model of the case was defined, modelling just the monitored span in $3 \mathrm{D}$ centred in a domain of $56 \times 50.7 \times 22 \mathrm{~m}$, preparing four structured meshes, made up of 163,368 to 2,812,940 elements. The first one was carried out using a Cooper scheme with an interval size of $0.4 \mathrm{~m}$ for the centre and $0.8 \mathrm{~m}$ to $1 \mathrm{~m}$ outside; the other three meshes were obtained adopting a ratio of $1 / 2$. The simulations were conduct in Fluent 6.3 with this specific initial condition: inlet velocity of $0.1 \mathrm{~m} / \mathrm{s}$, outdoor temperature of $295.15 \mathrm{~K}$ and the pavement temperature of $282.15 \mathrm{~K}$. From the results of each simulations, several velocity profile, among different positions, were selected in order to carry out a comparison between meshes: a clear stability of the results was obtained in most positions with more than $4.66 \times 10^{5}$ elements, corresponding to cell sizes of $0.2 \mathrm{~m}$ inside the greenhouse and $0.4 \mathrm{~m}$ to $1 \mathrm{~m}$ outside. The study of the indoor airflow dynamics were then conducted on a complete model of the greenhouse with three spans, with isothermal steady state simulations in 2D and 3D. The meshes were composed of 688,146 elements for the $3 \mathrm{D}$ case, and 13,414 cells for the 2D case.

The results of airflow simulations carried out with the two codes have been compared to verify their reliability. Air speed distributions along the central longitudinal axis of the inlet vents in the 3D models have been computed and compared. In both windows the velocity is equal for the two models at a distance of about $8.5 \mathrm{~m}$ from the greenhouse back façade. 2D simulation with FVM provide results consistent with $3 \mathrm{D}$ ones: peak inlet velocity in wall vent is $0.097 \mathrm{~m} \mathrm{~s}^{-1}$, in roof vent is $0.077 \mathrm{~m} \mathrm{~s}^{-1}$. Results of FEM analysis are significantly smaller, i.e., respectively $0.042 \mathrm{~m} \mathrm{~s}^{-1}$ and $0.054 \mathrm{~m} \mathrm{~s}^{-1}$.

A comparison of the internal airflow simulated has been carried out considering the vertical air velocity profile at the centre of the cultivation area (Figure 2). Below $2 \mathrm{~m}$ the 2D FVM and 3D FVM simulation results show a very small mean difference, equal to $0.00031 \mathrm{~m} \mathrm{~s}^{-1}$, while FEM simulation provide significantly lower values, both below and above the bench level. Between heights of $3 \mathrm{~m}$ and $4 \mathrm{~m}$ FEM 2D, FEM 3D and FVM 3D results are very similar, with average standard deviation of $0.00034 \mathrm{~m} \mathrm{~s}^{-1}$. Above $4 \mathrm{~m}$ the results show higher variability, in particular FVM $2 \mathrm{D}$ are remarkably greater than the other ones. Both $3 \mathrm{D}$ models provide a circular airflow pattern around a centre placed at the height of the side inlet vent. The FEM code indicates that this centre is in the south-eastern part of the span, while the FVM code provides it nearer to the central span. Both simulations show low values of velocity around the benches and, specifically, in the FEM results the area is characterized by still air.

These results, in analogy with previous researches (Mistriotis et al., 1997b), reproduce consistently the phenomenon for conditions when the solar radiation and the buoyancy effect are negligible. Moreover the results show the air flow following, from the windward lateral vent, the inside surface of the roof to the upper openings, more evident in FVM code. These results are in line with those obtained in scientific literature (Mistriotis et al., 1997b) through the wind-tunnel experiment for a single-span greenhouse.

\section{Conclusions}

The results led to define the most suitable solutions to set up computational models for the simulation of airflow patterns inside a greenhouse. Unsteady state thermal analyses have been adopted to validate modelling approach against experimental results. Mesh convergence analyses showed that mesh independency is achieved with elements size of $0.2 \mathrm{~m}$ for the volume inside the building and $1 \mathrm{~m}$ for the outdoor space, with a transition volume around the greenhouse. The FVM model adopted a structured mesh and achieved convergence with a smaller number of elements than the FEM model characterised by a mixed mesh. The comparisons between the results obtained through 3D FEM and 3D FVM simulations provided a substantial agreement of the velocity profiles, with a good agreement in the zones of inlet, characterised by the highest velocities. Nevertheless, in some limited zones characterised by slow airflow, the relative difference reaches $50 \%$, whereas the absolute difference have order of magnitude of $10^{-2} \mathrm{~m} \mathrm{~s}^{-1}$. The main difference of $2 \mathrm{D}$ models from 3D ones are due to the impossibility to account for airflows along the longitudinal direction of the greenhouse span, which proved to be not negligible at all.

The study provided a preliminary outline of the differences due to the adoption of various computational approaches. The results indicate also the opportunity to further develop the research through deeper experimental insights. The models developed could be adopted as references to investigate the role of further parameters, with particular regard to the temperature distribution in the cases when buoyancy phenomena may significantly affect the airflows dynamics.

\section{References}

Bartzanas T., Boulard T., Kittas C. 2004. Effect of vent arrangement on windward ventilation of a tunnel greenhouse. Biosyst. Eng. 88:479-90.

Benni S., Tassinari P., Bonora F., Barbaresi A., Torreggiani D. 2016. Efficacy of greenhouse natural ventilation: environmental monitoring and CFD simulations of a study case. Energy Build. 125:276-86.

Boulard T., Roy J.C., Lamrani M.A., Haxaire R. 1997. Characterising and modelling the air flow and temperature profiles in a closed greenhouse in diurnal conditions. In: A. Munack and H.J. Tantau (Eds.), Mathematical and control applications in agriculture and horticulture. Pergamon Press Ltd, Oxford, UK, pp 37-42.

Di Sabatino S., Buccolieri R., Pulvirenti B., Britter R. 2007. Simulations of pollutant dispersion within idealised urban-type geometries with CFD and integral models. Atmos. Environ. 41:8316-29.

He K.S., Chen D.Y., Sun L.J., Liu Z.L., Huang Z.Y. 2015. The effect of vent openings on the microclimate inside multi-span greenhouses during summer and winter seasons. Eng. Appl. Comput. Fluid Mech. 9:399-410.

Katsoulas N., Bartzanas T., Boulard T., Mermier M., Kittas C. 2006. Effect of vent openings and insect screens on greenhouse ventilation. Biosyst. Eng. 93:427-36.

Khaoua S.A.O., Bournet P.E., Migeon C., Boulard T., Chassériaux G. 2006. Analysis of greenhouse ventilation efficiency based on computational fluid dynamics. Biosyst. Eng. 95:83-98.

Mistriotis A., Arcidiacono C., Picuno P., Bot G.P.A., ScarasciaMugnozza G. 1997a. Computational analysis of ventilation in greenhouses at zero- and low-wind-speeds. Agric. For. Meteorol. 88:121-35.

Mistriotis A., Bot G.P.A., Picuno P., Scarascia-Mugnozza G., 
1997b. Analysis of the efficiency of greenhouse ventilation using computational fluid dynamics. Agric. For. Meteorol. $85: 217-28$

Mistriotis A., Picuno P., Bot G.P.A., Scarascia-Mugnozza G., 1997c. Computational study of the natural ventilation driven by buoyancy forces. In: A. Munack and H.J. Tantau (Eds.),
Mathematical and control applications in agriculture and horticulture. Pergamon Press Ltd, Oxford, UK, pp 67-72.

Rico-Garcia E., Soto-Zarazua G.M., Alatorre-Jacome O., TorreGea G.A.D. la, Gomez-Melendez D.J. 2011. Aerodynamic study of greenhouses using computational fluid dynamics. Int. J. Phys. Sci. 6:6541-7. 